Eixo Roda, Belo Horizonte, v. 28, n. 2, p. 231-236, 2019

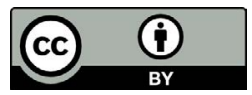

\title{
SOARES, Carmen (coord.). BiblioAlimentaria: alimentação, saúde e sociabilidade à mesa no acervo bibliográfico da Universidade de Coimbra. Coimbra: Imprensa da Universidade de Coimbra, 2018. 170 p. ISBN: 2183-6523.
}

Isabel Drumond Braga

Universidade de Lisboa, Faculdade de Letras e CIDEHUS-UE, Lisboa / Portugal isabeldrumondbraga@hotmail.com

Em 2008, por iniciativa de Maria José Azevedo Santos, começou a funcionar o Mestrado em Alimentação: Fontes, Cultura e Sociedade, na Faculdade de Letras da Universidade de Coimbra. Volvidos alguns anos, em 2015, foi a vez de aparecer, na mesma instituição, o Doutoramento em Patrimónios Alimentares: Culturas e Identidades, coordenado por Carmen Soares. Na Faculdade de Letras da Universidade de Lisboa funciona, desde 2009, uma unidade curricular intitulada História da Alimentação, da responsabilidade da signatária. Naturalmente que a investigação e a produção científica dos docentes universitários devem estar na base do fomento de determinadas áreas de estudo, para que possam orientar mestrandos, doutorandos e pós doutorandos de forma adequada e, desse modo, produzir-se conhecimento rigoroso e atualizado.

A obra BiblioAlimentaria: alimentação, saúde e sociabilidade à mesa no acervo bibliográfico da Universidade de Coimbra, publicada em abril de 2018, resulta do esforço pioneiro de identificar fontes e bibliografia para o estudo da alimentação, na ótica da história, a partir do rico acervo da Universidade de Coimbra. Recorde-se que o mestrado e o doutoramento ali ministrados contaram desde o início com uma unidade curricular intitulada Fontes e Metodologia para a História da Alimentação, da responsabilidade de Maria José Azevedo Santos. A docente, enquanto diretora do Arquivo da Universidade de Coimbra, lecionou a referida disciplina no próprio arquivo, o que permitiu aos discentes o contacto direto com os documentos, e que o trabalho agora apresentado resultou 
diretamente de uma exposição realizada em março de 2016, no âmbito da Semana Cultural da Universidade de Coimbra. Nessa ocasião, foi dado a conhecer parte do espólio documental e bibliográfico existente na instituição. Deste modo, o livro cruza diversas valências da atividade produzida no âmbito do ensino superior, a saber, o ensino, a investigação e a extensão universitária.

Perante o leitor, foram apresentados 101 títulos sobre alimentação nas suas vertentes de produção, consumo, comércio, indústria, saúde e bem-estar, agrupados em cinco categorias: 1) memória gastronómica, 2) contabilidade e administração, 3) medicina e farmacopeia, 4) agricultura, comércio e indústria, e 5) sociedade e etiqueta. A obra, que contou com um prefácio de José Augusto Cardoso Bernardes, diretor da Biblioteca Geral da Universidade de Coimbra, foi dividida em três partes. Na primeira, podem ver-se as referências bibliográficas completas organizadas por Ana Maria Bandeira (relativas ao Arquivo da Universidade de Coimbra) e supervisionadas por Maria Luísa Machado (as que se referem a obras à guarda da Biblioteca Geral da Universidade de Coimbra); na segunda, a descrição do conteúdo dos títulos, de extensão muito variável e com formas de citar distintas, o que teria valido a pena uniformizar. Nesta seção, os verbetes foram elaborados por Carmen Soares, Cristina Padez, João Pedro Gomes e Raquel Fino Seiça; e, na terceira, alguns estudos de caso sobre obras expostas, os quais não são particularmente diferentes de algumas das entradas mais extensas apresentadas para outras obras na seção anterior, da autoria de Ana Maria Leitão Bandeira, Maria Helena da Cruz Coelho, Irene Vaquinhas e Carmen Soares.

No grupo dedicado às memórias gastronómicas podem encontrar-se edições seiscentistas e setecentistas, verdadeiras raridades bibliográficas, embora uma parte das quais não sejam primeiras edições. Destaquem-se, entre os autores estrangeiros, Ateneu de Náucrates, Bartolomei Scappi e Vincent La Chapelle; entre os portugueses, vale a pena distinguir Domingos Rodrigues, autor do mais editado livro português de cozinha da Época Moderna (BRAGA, 2017), Lucas Rigaud, seu crítico, e, para o século XX, autores como Sofia da Silva, Isalita (pseudónimo de Maria Isabel de Sousa Campos Henriques e de Angela Carvajal y Pinto Leite Telles da Silva), como foi devidamente esclarecido (SOARES, 2018, p. 52); António Maria de Oliveira Bello, conhecido como Ollebona; sem esquecer autoras tão diferentes como Berta Rosa Limpo e Rosa Maria, na verdade o pseudónimo de Gaspar de Almeida, conforme foi apurado recentemente (BRAGA; PILLA, 2018). Neste apartado, duas referências 
merecem ser salientadas pelo seu pioneirismo e, paradoxalmente ou não, pelo insucesso editorial. Referimo-nos à obra anónima Arte nova e curiosa para conserveiros, confeiteiros e copeiros, o primeiro livro exclusivamente dedicado a doçaria, publicado em 1788, e que mereceu uma nova edição acompanhada por um estudo (BRAGA, 2004), e à primeira revista de culinária, publicada em Portugal nos anos de 18361837, a Annona ou Mixto-curioso, constituída, contudo, por receitas não originais. Foi necessário esperar mais de um século para os periódicos de culinária serem publicações de ampla tiragem e consequente êxito editorial. Sobre culinária vegetariana foram incluídos dois títulos, em segunda edição, um de Maria Sofia da Silva, O Cozinheiro prático e outro de Maria Cândida de Albuquerque Cardoso, Alimentação saudável pelo naturismo moderno: culinária prática, um livro de receitas presente na seção sobre medicina e farmacopeia. Excluídos ficaram dois periódicos fundacionais da bibliografia vegetariana e naturista portuguesa, que incluíram receitas, O Vegetariano (1909-1935) e o Almanaque Vegetariano (1913-1922), ambos dirigidos por Amílcar de Sousa.

No pequeno apartado dedicado aos manuscritos sobre contabilidade e administração, realce para três deles. $\mathrm{O}$ registo do pagamento de propinas dos doces enviados pela Universidade de Coimbra ao Conselho Supremo da Coroa, em Madrid (1629), que se refere ao pagamento do transporte dos mesmos; um inventário da cozinha do Real Colégio de São Paulo (1778), dando a conhecer a bateria de cozinha e os têxteis domésticos; e o livro de registos dos preços almotaçados nas feiras (17961809), particularmente interessante pelo arrolamento dos géneros e dos seus preços, como referiu Ana Maria Leitão Bandeira, na última parte da obra (SOARES, 2018, p. 144).

Os itens dedicados à medicina e à farmacopeia contam com nomes da Antiguidade, tais como Hipócrates, Dioscórides e Galeno, a par de autores de tratados de bromatologia e de farmacopeias, da Época Moderna, tais são os casos de Amato Lusitano, Fernão Solis da Fonseca, Francisco da Fonseca Henriques, Francisco Morato Roma e Caetano de Santo António. Trata-se de um relevante conjunto de obras em que se salienta a ligação entre medicina e saúde, apoiada nas propriedades dos alimentos e na defesa da ingestão de certos géneros como forma de contribuir significativamente para a cura de diversas enfermidades. Refiram-se ainda as papeletas dos doentes dos Hospitais da Universidade de Coimbra (1878). Excluídas e merecedoras de presença neste apartado, as obras de divulgação médica de 
Amílcar de Sousa, um dos pioneiros e o maior ativista do vegetarianismo e do naturismo em Portugal (BRAGA, 2019).

$\mathrm{Na}$ penúltima seção, sobre obras de agricultura, comércio e indústria, destaque-se a Gazeta das aldeias (1896), um periódico agrícola no qual escreveram personalidades de diferentes áreas do conhecimento sobre políticas agrícolas, em que se abordaram temas tão diversificados como agricultura, silvicultura, fruticultura, viticultura, apicultura, recomendações de saúde, a par de informações sobre conservação e confecção de alimentos, incluindo receitas de culinária. O jornal mereceu a atenção de Maria Helena da Cruz Coelho na última parte da obra (SOARES, 2018, p. 148-154). Este apartado contou ainda com diversos documentos relativos a fábricas de massas alimentícias e de refinação de açúcar, em Coimbra.

Finalmente, a seção sobre sociabilidade e etiqueta reuniu obras nacionais e estrangeiras dos séculos XIX e XX, designadamente manuais de etiqueta e obras de economia doméstica. No primeiro caso destaque para a de J. I. Roquete, Código do bom tom, e, no segundo, para a de Virgínia de Castro e Almeida, Como devo governar a minha casa. De fora ficou Maria Amália Vaz de Carvalho, Arte de viver na sociedade (BRAGA; BRAGA, 2004), uma obra de referência entre este tipo de textos normativos, também ela existente no espólio bibliográfico da Universidade de Coimbra. Foram ainda incluídas duas publicações periódicas que dificilmente se podem considerar obras dedicadas às matérias antes enunciadas, como aliás o leitor que não esteja familiarizado com a matéria pode verificar pela apresentação a cargo de João Pedro Gomes (SOARES, 2018, p. 138-139). Recorde-se que a Ilustração portuguesa (1903-1993) foi uma das revistas de maior difusão no Portugal da primeira metade do século XX, e a Menina e moça (1947-1974) foi uma das publicações da Mocidade Portuguesa Feminina (cf. FIDALGO, 2003; BRAGA; BRAGA, 2012).

Um estudo de caso, na terceira parte da obra, da autoria de Carmen Soares, sobre a obra Cosinha Portugueza, cuja $2^{\mathrm{a}}$ edição datou de 1902, motivou uma relevante ligação da Universidade de Coimbra ao mundo empresarial. A autora, classicista de formação, estudou aquele livro de cozinha, no qual constam cinco receitas ligadas ao meio universitário, quatro pratos salgados, a saber, "bacalhau à estudantina", "bacalhau à doutora", "coelho à estudantina" e "omeleta de estudante" e um doce, "biscoitos académicos". Trata-se de uma obra com um discurso culinário nacionalista, prática que se irá acentuar durante $\mathrm{o}$ 
Estado Novo (SOBRAL, 2007), na qual coincidem receitas de origem e inspiração estrangeira, a par de outras de cunhos nacional e regional. Ora, foi precisamente a receita de "biscoitos académicos", apresentada agora numa releitura da receita original do início do século XX, que permitiu, juntando uma receita setecentista de "conservas de pêssegos de Coimbra" criar novos biscoitos, num projeto de colaboração entre o curso de doutoramento, a Reitoria da Universidade de Coimbra e a empresa Vasco da Gama Pastelarias. A Universidade de Coimbra é a proprietária da marca "Biscoitos Académicos", com o número de registo 59122 do Instituto Nacional da Propriedade Industrial (cf. BISCOITOS..., [201-]). $\mathrm{O}$ exclusivo da produção cabe às referidas pastelarias Vasco da Gama.

Embora a obra dê a conhecer apenas parte do espólio da Universidade de Coimbra, sobre os temas já elencados, tem relevância dentro e fora de Portugal, uma vez que, como já se referiu no início, ali se formam mestres e doutores, alguns deles estrangeiros e, de entre estes, um número considerável de brasileiros. Significa isto que o conhecimento de uma publicação como a que aqui é objeto de resenha é relevante para todos os estudiosos do tema, constituindo um instrumento de trabalho que permite aos investigadores analisar e debater a literatura da especialidade, oriunda de espaços e tempos diferenciados.

Em conclusão, a obra BiblioAlimentaria: alimentação, saúde e sociabilidade à mesa no acervo bibliográfico da Universidade de Coimbra contou com o trabalho levado a cabo por historiadores, arquivistas e bibliotecários, a que se juntaram pessoas com outras formações. $\mathrm{O}$ resultado final é um produto no qual coexiste a qualidade dos textos e da apresentação gráfica e, em especial, um instrumento de trabalho relevante para todos os que têm interesse na história da alimentação. O facto de ter proporcionado o registo de um produto, os "biscoitos académicos", revela o bom uso da investigação histórica, sem o qual não teria sido possível fundamentar a mescla tradição e criatividade.

\section{Referências}

BISCOITOS Académicos. [S. l.: s. n., 201-]. Disponível em: https://www. biscoitosacademicos.com/. Acesso em: 22 maio 2018.

BRAGA, I. D. Das origens do vegetarianismo em Portugal: Amílcar de Sousa (1876-1940), o apóstolo verde. Lisboa: Biblioteca Nacional de Portugal, 2019. 
BRAGA, I. D. Domingos Rodrigues e a arte de cozinha: uma vida pouco conhecida, uma obra muito usada. In: BRAGA, I. D. (coord.). Primeiro tratado de cozinha: arte de cozinha. Lisboa: Círculo de Leitores, 2017. p. 7-48.

BRAGA, I. D. O primeiro livro de doçaria portuguesa (1788). In: ARTE nova e curiosa para conserveiros, confeiteiros e copeiros e mais pessoas que se ocupam em fazer doces e conservas com frutas de várias qualidades e outras muitas receitas particulares que pertencem à mesma arte. Sintra: Colares Editora, 2004, p. 9-22.

BRAGA, I. D.; BRAGA, P. D. A mocidade portuguesa feminina e a formação culinária em menina e moça (1947-1962). Cadernos Pagu, Campinas, n. 39, p. 201-226, 2012. DOI: https://doi.org/10.1590/S010483332012000200007.

BRAGA, I. D.; BRAGA, P. D. Civilidades. Porquê? Para quê? Para quem?. In: CARVALHO, M. A. V. Arte de viver na sociedade. Sintra: Colares Editora, 2004. p. 9-42.

BRAGA, I. D.; PILLA, M. C. A. P. Rosa Maria para a elite, Rosa Maria para o povo: culinária brasileira e culinária portuguesa na primeira metade do século XX. Revista de História, São Paulo, n. 177, p. 1-28, 2018.

FIDALGO, M. I. V. Menina e moça: um ideal de formação feminina (1960-1970). Lisboa: Organizações não Governamentais do Conselho Consultivo da Comissão para a Igualdade e para os Direitos das Mulheres, 2003.

SOARES, C. (coord.). BiblioAlimentaria: alimentação, saúde e sociabilidade à mesa no acervo bibliográfico da Universidade de Coimbra. Coimbra: Imprensa da Universidade de Coimbra, 2018. 170 p. ISBN: 2183-6523.

SOBRAL, J. M. Nacionalismo, culinária e classe: a cozinha portuguesa da obscuridade à consagração (séculos XIX-XX). Revista do Centro de Estudos Rurais-RURIS, Campinas, n. 1-2, p. 13-52, 2007.

Recebido em: 17 de outubro de 2018.

Aprovado em: 22 de março de 2019. 